\title{
ARMAZENAMENTO REFRIGERADO DA UVA DE MESA 'ROMANA' (A1105) CULTIVADA SOB COBERTURA PLÁSTICA ${ }^{1,2}$
}

\author{
JORGE LULU ${ }^{3}$, JOSALBA V. CASTRO ${ }^{4}$, MÁRIO J. PEDRO JÚNIOR ${ }^{5}$
}

\begin{abstract}
RESUMO: A videira é uma das principais fruteiras cultivadas em todo o mundo e atualmente a preferência por uvas do tipo "sem sementes" ou "apirênicas" vem aumentando gradativamente no mercado interno brasileiro. A cultivar 'Romana' (A1105) tem mostrado grande potencial como nova alternativa de uva de mesa apirênica na região de Jundiaí - SP. No entanto, a qualidade dos cachos tem sido afetada pela ocorrência de chuvas na época da colheita, propiciando a incidência de rachaduras nas bagas ("cracking") e podridões. Visando a solucionar essa dificuldade, foram conduzidos experimentos de campo em vinhedo cultivado em cortina dupla e sob cobertura plástica. Após a colheita, foram coletadas oito amostras com seis cachos cada, que foram armazenadas a $3{ }^{\circ} \mathrm{C}$ e submetidas a avaliações de qualidade por um período máximo de 36 dias. A perda de massa ultrapassou o valor de 6\% após três semanas de armazenamento refrigerado, quando apresentou sinais de murchamento das bagas, concluindo-se que o período máximo de armazenamento em câmara fria para a cultivar 'Romana' (A1105) foi de 21 dias.
\end{abstract}

PALAVRAS-CHAVE: Vitis sp., perda de massa, podridões.

\section{COLD STORAGE OF 'ROMANA' (A1105) TABLE GRAPE CULTIVATED UNDER PLASTIC COVER}

\begin{abstract}
The grapevine is one of the most cultivated fruit crop and nowadays the preference for seedless grapes is gradualy increasing in the Brazilian internal market. The table grape cultivar 'Romana' (A1105) has been showing potential as a new option for the growers from Jundiaí - SP, Brazil, as a seedless grape. However the bunch quality has been affected by rain at the harvest allowing the incidence of cracking and bunch rot. Aiming to solve this problem a field trial was carried out with grapes cultivated under plastic cover and Geneva Double Curtain training system. After harvest, eight samples of six bunches each were taken and stored at $3{ }^{\circ} \mathrm{C}$ and evaluated for quality during a period of 36 days. After three weeks of storage, the weight loss was higher than $6 \%$, showing bunch fade and the rot bunch increased significantly. It was concluded that maximum shelf life for the 'Romana' (A1105) table grape cultivar was 21 days.
\end{abstract}

KEYWORDS: Vitis sp., weight loss, bunch rot.

\footnotetext{
${ }^{1}$ Extraído da dissertação de Mestrado do primeiro autor. Projeto financiado pela CAPES.

2 Trabalho apresentado no XXXIII Congresso Brasileiro de Engenharia Agrícola, São Pedro - SP, 2004.

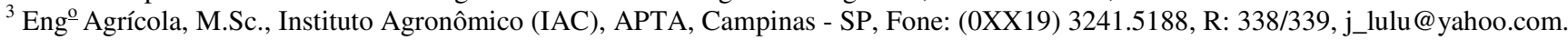
Bolsista da CAPES.

${ }^{4}$ Eng ${ }^{\mathrm{a}}$ Agrônoma, Pesquisadora Científica, Instituto Agronômico (IAC), APTA, Campinas - SP.

${ }^{5}$ Eng ${ }^{o}$ Agrônomo, Pesquisador Científico, Instituto Agronômico (IAC), APTA, Campinas - SP. Bolsista do CNPq.

Recebido pelo Conselho Editorial em: 6-4-2004

Aprovado pelo Conselho Editorial em: 12-12-2004
}

Eng. Agríc., Jaboticabal, v.25, n.2, p.481-487, maio/ago. 2005 


\section{INTRODUÇÃO}

Ocupando atualmente área de 7,5 milhões de hectares, a videira é uma das principais fruteiras cultivadas no mundo, com produção anual de 62 milhões de toneladas (FAO, 2004), das quais 8,5 milhões são de uva para mesa. Segundo a FAO (2004), o Brasil apresenta área plantada em torno de 68 mil hectares, com produção média de 1,065 milhão de toneladas, representando cerca de $2 \%$ da produção mundial. No período de 1998 a 2003, houve incremento de 37,6\% na produção nacional e de 22,4\% na produtividade. No Estado de São Paulo, a produção de uvas de mesa vem mostrando tendência de crescimento nos últimos anos, e a grande maioria das uvas produzidas (99\%) tem como objetivo o mercado de frutas para mesa (IEA, 2003).

Analisando o mercado brasileiro de frutas de mesa, é possível perceber uma exigência cada vez maior dos consumidores nacionais por uvas de melhor qualidade, não somente em relação ao aspecto visual, mas também ao sabor, aroma e consistência, além de preferência por uvas do tipo "sem sementes" ou "apirênicas". De acordo com GRANGEIRO et al. (2002), há aproximadamente oito anos algumas empresas da região do Vale do São Francisco iniciaram o cultivo comercial de uvas sem sementes por meio do plantio de uma variedade americana, patenteada pela empresa Sun World, denominada 'Superior Seedless' ou 'Sugraone', também conhecida no Vale do São Francisco como 'Festival'.

O INSTITUTO AGRONÔMICO (IAC) possui em seu banco de germoplasma diferentes variedades de uvas de mesa, dentre as quais a 'Romana' (A 1105), que é uma planta vigorosa e produtiva, com cachos médios a grandes, bem compactos e cônicos, bagas esverdeadas, médias a grandes mesmo sem ácido giberélico, de textura crocante e com agradável sabor neutro (POMMER, 2001). A cultivar A 1105 ('Romana') tem mostrado grande potencial como nova alternativa de uva de mesa apirênica na região de Jundiaí - SP. No entanto, de acordo com SOUZA \& MARTINS (2002), a qualidade dos cachos tem sido afetada pela ocorrência de chuvas na época da colheita, propiciando rachaduras nas bagas ("cracking") e incidência de podridões. Para evitar a chuva nos cachos na época da colheita e conseqüente melhoria de qualidade, o cultivo protegido surge como alternativa, principalmente tratando-se de uva fina de mesa.

O cultivo em ambiente protegido tem como finalidade principal a proteção contra as adversidades climáticas e, em conseqüência, obtêm-se precocidade nas colheitas, aumento na produtividade e frutos de melhor qualidade, com a opção de explorar as culturas durante todo o ano (CERMEÑO, 1990 e CUNHA, 2001). Por meio da utilização dessa técnica de maneira eficiente e econômica, é possível conseguir colheitas que excedem sensivelmente as que se obtêm em condições de campo (OLIVEIRA, 1995 e CUNHA, 2001).

Os produtos colhidos de cultivo em ambiente protegido, embora tenham melhor qualidade, ainda podem apresentar problemas pós-colheita. No caso das uvas, os principais problemas estão relacionados à incidência e ao agravamento de podridões e à desidratação dos cachos. Portanto, a refrigeração tem sido utilizada como prática de armazenamento por permitir o prolongamento do período de comercialização das uvas, pois, como frutos não-climatéricos, essa prática acarreta diminuição na taxa de deterioração (GORGATTI NETTO et al., 1993).

Levando-se em consideração a viabilidade do cultivo da uva de mesa 'Romana' (A1105) cultivada sob cobertura plástica, foi realizada a presente pesquisa na região de Jundiaí - SP, com o objetivo de analisar a vida de prateleira dessa cultivar em câmara fria.

\section{MATERIAL E MÉTODOS}

O ensaio foi realizado no Centro Avançado de Pesquisa Tecnológica do Agronegócio de Frutas do INSTITUTO AGRONÔMICO (IAC), localizado no município de Jundiaí - SP, com $23^{\circ} 10^{\prime}$ de 
latitude $\mathrm{S}$ e $46^{\circ} 53^{\prime}$ de longitude $\mathrm{W}$, a uma altitude média de $750 \mathrm{~m}$, em vinhedos de 'Romana' (A 1105) conduzidos em sistema de cortina dupla e sob cobertura plástica, no período de dezembro de 2003 a janeiro de 2004. A estrutura da cobertura foi instalada logo acima da copa das plantas, com o objetivo de apenas evitar a chuva direta nos cachos, sendo o seu formato "em arco". Foi utilizado o plástico de filme de polietileno de baixa densidade (PEBD), de $150 \mu \mathrm{m}$ de espessura, transparente e com tratamento contra raios ultravioleta (UV). Foram instaladas as coberturas em três linhas de $6 \mathrm{~m}$ de comprimento, com seis plantas cada linha, aproximadamente 40 dias antes da colheita dos frutos.

A colheita foi manual, fazendo-se a seleção e a toalete dos cachos, descartando-se as bagas que eventualmente apresentaram algum tipo de defeito. Durante a colheita, foram retiradas oito amostras com seis cachos cada amostra, sendo os cachos etiquetados e pesados. Cada amostra foi acondicionada (sem pré-resfriamento) em caixa de papelão, tipo exportação, peça única, com dimensões externas de $470 \mathrm{~mm}$ x $290 \mathrm{~mm}$ x $120 \mathrm{~mm}$, quatro furos de $25 \mathrm{~mm}$ de diâmetro, oito aberturas de $60 \mathrm{~mm}$ x $10 \mathrm{~mm}$ e capacidade para $6 \mathrm{~kg}$ de uvas, totalizando oito caixas. As caixas foram imediatamente colocadas e mantidas em câmara fria com temperatura constante de $3{ }^{\circ} \mathrm{C}$ e umidade relativa do ar entre 90 e $95 \%$, com dimensões úteis de 3,5 m de comprimento x 1,2 m de largura x 2,5 m de altura. Retirou-se, ao acaso, uma amostra (uma caixa com seis cachos de uvas) em oito períodos de armazenamento refrigerado $(4 ; 7 ; 11 ; 14 ; 18 ; 21 ; 28$ e 36 dias) para avaliações de perda de massa e também de defeitos graves como: uvas imaturas (teor de sólidos solúveis totais inferior a $14{ }^{\circ} \mathrm{Brix}$ ), podridões (podridãoamarga e podridão-mole) e danos profundos. A realização de avaliações espaçadas em períodos diferentes entre cada uma, ou seja, até 21 dias (espaçamento de 3 a 4 dias) e de 21 a 36 dias (espaçamento de 7 a 8 dias) foi feita, pois, no início, a intensidade das alterações fisiológicas são maiores e, por isso, foram monitoradas em intervalos menores. Já nos últimos períodos, essas mesmas alterações ocorrem mais lentamente.

A avaliação da contaminação microbiana para a identificação dos agentes causais dessas podridões (podridão-amarga e podridão-mole) foi feita visualmente, ou seja, de acordo com a sintomatologia presente nos cachos. Assim, segundo POMMER (2003), a podridão-amarga possui como agente causal o fungo Melanconium fuligineum, o qual afeta as bagas por meio do pedicelo, no início da maturação, continuando seu desenvolvimento no armazenamento e comercialização da uva. Os frutos atacados apresentam pontuações negras em círculos concêntricos, representadas pelos acérvulos do fungo. As bagas doentes apodrecem e caem e, se experimentadas, apresentam sabor amargo. Já a podridão-mole tem como agente causal o fungo Rhizopus spp.; a doença inicia-se com uma mancha circular aquosa, e a cutícula se desfaz com facilidade. O tecido afetado da uva torna-se mole, aquoso, liberando um suco com forte odor ácido ou fermentado e, em pouco tempo, toma as bagas adjacentes.

Para a avaliação de perda de massa, os seis cachos foram pesados individualmente, sendo a massa atual (de cada período sob refrigeração) subtraída da massa inicial (tempo zero), expressando-se os valores em porcentagem. Foi avaliada a perda de massa durante os oito períodos de armazenamento refrigerado, completando com análise de variância, utilizando-se do programa Sistaux e análise de regressão da perda de massa durante todo o período na câmara fria.

$\mathrm{Na}$ avaliação do teor de sólidos solúveis totais (SST), para a verificação da existência de uvas imaturas, a determinação foi feita por meio da leitura direta em refratômetro manual da marca Shibuya, de 0 a $32^{\circ}$ Brix, com escala de $0,2^{\circ}$ Brix. Foram consideradas imaturas as uvas que apresentaram valores de teor de sólidos solúveis totais (SST) inferiores a $14^{\circ}$ Brix (BRASIL. Ministério..., 2002). A verificação do teor de SST foi realizada retirando-se de cada cacho quatro bagas, sendo uma da parte superior, duas da parte média e uma da parte inferior, seguindo as normas do regulamento técnico de identidade e de qualidade para a classificação da uva fina de mesa (BRASIL. Ministério..., 2002). Obteve-se o teor de SST médio de cada amostra, em cada período de 
coleta e também durante todo o período de armazenamento refrigerado, completando com análise de variância, utilizando-se do programa Sistaux.

Para as avaliações feitas por contagem do número de bagas, foi necessário, em primeiro lugar, estimar a massa média de uma baga, a qual fosse representativa dos seis cachos de cada amostra. Essa massa foi estimada, pesando-se o total de bagas desprendidas dos engaços (degrana) em cada caixa (amostra), dividindo-se esse valor pelo número de bagas desprendidas. Além disso, encontrou-se a porcentagem de degrana natural média para todo o período de armazenamento refrigerado.

No presente experimento, as avaliações de podridões (podridão-amarga e podridão-mole) e danos profundos foram feitas por contagem do número de bagas com esses defeitos. De acordo com as normas do regulamento técnico de identidade e de qualidade para a classificação da uva fina de mesa (BRASIL. Ministério..., 2002), considera-se como "podridão" danos patológicos ou fisiológicos que impliquem qualquer grau de decomposição, desintegração ou fermentação dos tecidos. O mesmo regulamento cita como "dano profundo" lesões de origens diversas que causem rompimento da epiderme da baga. Obtendo a massa média de uma baga para cada amostra, foi possível obter a porcentagem da massa total de cada amostra com podridão ou dano profundo.

Considerando-se os "defeitos graves" (uvas imaturas, podridões e danos profundos) para cada período de armazenamento, classificaram-se as amostras por Categoria (Extra, I, II ou III), de acordo com o regulamento técnico de identidade e de qualidade para a classificação da uva fina de mesa (BRASIL. Ministério..., 2002). Com isso, foi possível avaliar, de acordo com a qualidade das amostras em cada período, a vida de prateleira da cultivar 'Romana' (A1105), verificando o tempo máximo de armazenamento em câmara fria. Assim, considerou-se como limite máximo tolerado a classificação da uva na Categoria I. Além disso, de acordo com as recomendações de GORGATTI NETTO et al. (1993) e CASTRO (1999), essa vida de prateleira também foi determinada analisando-se a perda de massa das amostras, cuja tolerância é de, no máximo, $6 \%$.

\section{RESULTADOS E DISCUSSÃO}

Na Tabela 1, são apresentados os resultados das avaliações de parâmetros de qualidade das amostras de 'Romana' durante todo o período em câmara fria (36 dias), dando ênfase aos considerados "defeitos graves" (uvas imaturas, podridões e danos profundos). Primeiramente, foi possível observar que, em nenhum dos períodos de armazenamento refrigerado, ocorreu o aparecimento de uvas imaturas, ou seja, com teor de sólidos solúveis totais (SST) inferior a $14^{\circ}$ Brix (média de cada amostra). O coeficiente de variação (CV) entre os cachos das amostras foi de 11,15\% (médio), mostrando a homogeneidade dos cachos. Durante todo o período de armazenamento, os valores de SST não apresentaram tendência de acréscimo, fato esperado, uma vez que a uva não é um fruto climatérico e por isso mantém o teor de SST. Deve-se ressaltar que o teor de SST médio durante todo o período de armazenamento refrigerado foi de $15,2^{\circ} \mathrm{Brix}$, valor superior ao mínimo exigido para uva fina de mesa, que é de $14^{\circ}$ Brix (BRASIL. Ministério..., 2002).

Também foi verificado que, a partir dos 21 dias em câmara fria, houve aumento considerável de cachos que apresentaram podridões e danos profundos (Tabela 1). Aos 28 dias, 1,8\% da amostra apresentou podridões e 5,4\% apresentaram algum tipo de dano profundo. Já aos 36 dias, ocorreu incremento para $6,1 \%$ na incidência de podridões e para 9,8\% na ocorrência de danos profundos. Tais índices fazem com que, de acordo com o regulamento técnico de identidade e de qualidade para a classificação da uva fina de mesa (BRASIL. Ministério..., 2002), a amostra retirada aos 28 dias fosse classificada na Categoria II e, aos 36 dias, na Categoria III. Considerando-se isoladamente a porcentagem de degrana natural, que pela norma de uva fina de mesa é qualificada como um tipo de "defeito leve", observou-se valor médio de 8,2\% durante todo o período de armazenamento refrigerado, sendo classificadas na Categoria I. No entanto, como, de acordo com a norma, "o defeito 
grave, isoladamente, define a categoria", consideraram-se, neste experimento, apenas os "defeitos graves" para efeito de classificação das uvas. A classificação das amostras por categoria pode ser vista na Tabela 1 e na Figura 1a.

Com relação à perda de massa (Figura 1b), observou-se que, a partir dos mesmos 21 dias de armazenamento, a perda de massa superou o índice de 6\% (limite de turgidez das bagas). Segundo GORGATTI NETTO et al. (1993) e CASTRO (1999), quando a perda de massa é de 4 a 5\%, as bagas começam a apresentar enrugamento, fato esse observado no presente experimento. A análise de variância da porcentagem de perda de massa revelou efeito significativo a $1 \%$ de probabilidade entre os períodos de armazenamento refrigerado, sendo o coeficiente de variação médio entre os cachos das amostras igual a 16,28\%. Os dados foram ajustados por regressão linear (Figura 2), com coeficiente de determinação de 0,96 .

TABELA 1. Avaliação de qualidade e classificação das amostras de uva 'Romana' (A1105) durante o período de armazenamento refrigerado.

\begin{tabular}{cccccc}
\hline \multirow{2}{*}{$\begin{array}{c}\text { Período de } \\
\begin{array}{c}\text { Armazenamento } \\
\text { (dias) }\end{array}\end{array}$} & \multicolumn{4}{c}{ Defeitos Graves } & Classificação \\
\cline { 2 - 5 } & Imatura (\%) & Podridão (\%) & Dano Profundo (\%) & Total de Defeitos Graves (\%) & Categoria \\
\hline 4 & 0 & 0,6 & 1,0 & 1,6 & Extra \\
7 & 0 & 0,3 & 1,3 & 1,6 & Extra \\
11 & 0 & 0,9 & 1,7 & 2,6 & I \\
14 & 0 & 0,3 & 2,1 & 2,4 & I \\
18 & 0 & 1,3 & 2,8 & 4,1 & I \\
21 & 0 & 0,3 & 2,3 & 2,6 & II \\
28 & 0 & 1,7 & 5,4 & 7,1 & III \\
\hline
\end{tabular}

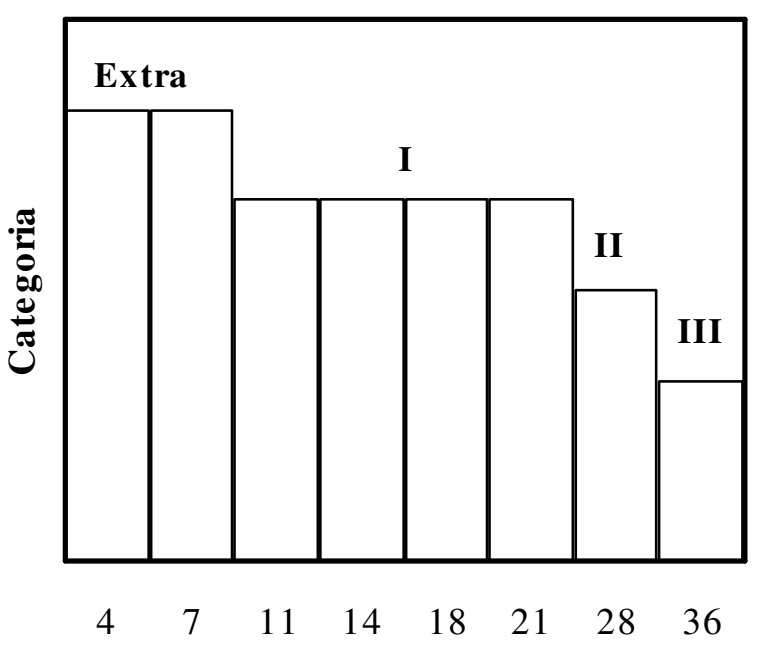

Dias na câmara fria

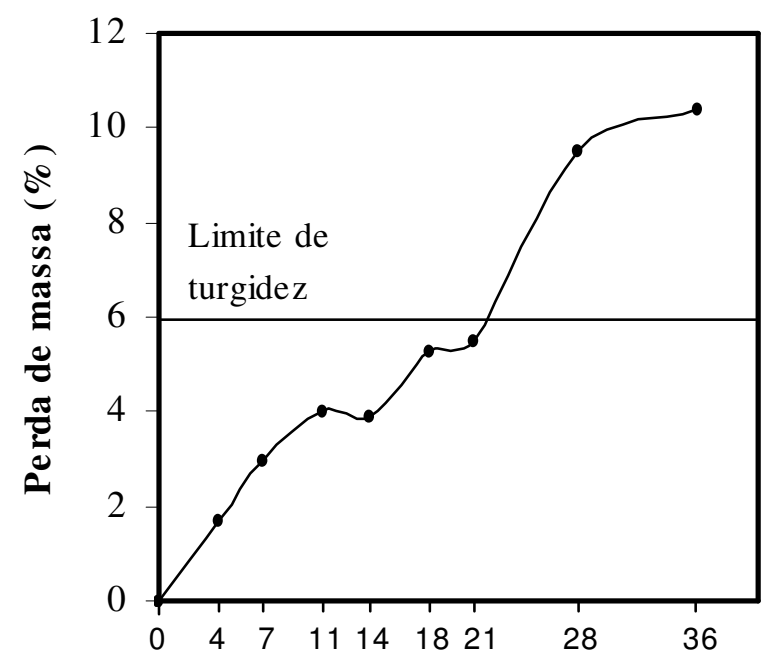

Dias na câmara fria

(a)

FIGURA 1. Classificação (a) e perda de massa (b) das amostras de uva 'Romana' (A1105) durante o período de armazenamento refrigerado. 


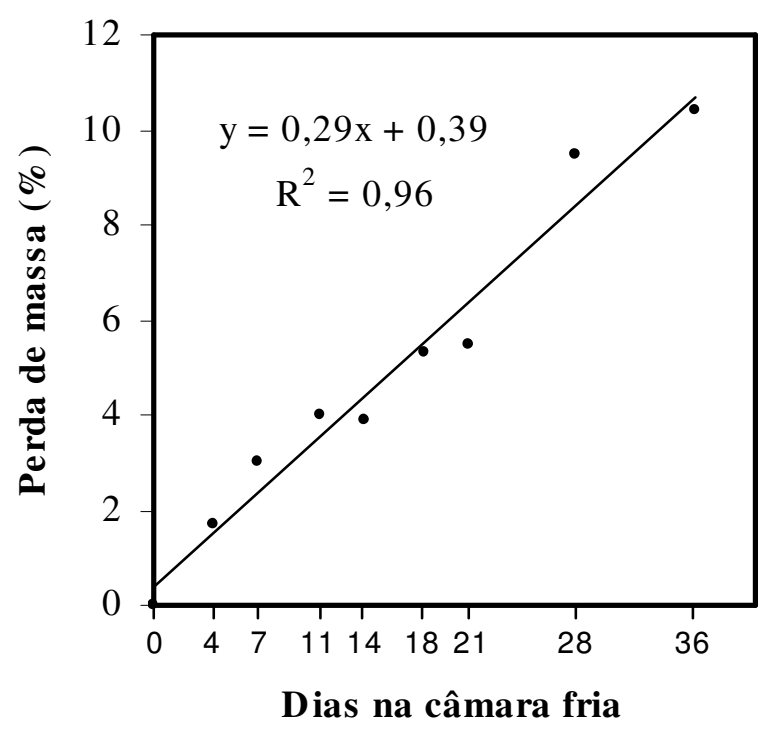

FIGURA 2. Regressão linear da perda de massa das amostras de uva 'Romana' em função do período de armazenamento refrigerado.

Com esses resultados, verificou-se que a cultivar 'Romana' (A1105) cultivada sob cobertura plástica pode ser armazenada em câmara fria por até 21 dias (três semanas), mantendo-se na Categoria I, de acordo com o regulamento técnico de identidade e de qualidade para a classificação da uva fina de mesa (BRASIL. Ministério..., 2002).

\section{CONCLUSÕES}

A uva fina de mesa 'Romana' (A1105), cultivada sob cobertura plástica, quando armazenada em câmara fria (temperatura de $3{ }^{\circ} \mathrm{C}$ e $90-95 \%$ de UR), possui vida de prateleira de 21 dias.

\section{REFERÊNCIAS}

BRASIL. Ministério da Agricultura, Pecuária e Abastecimento. Instrução normativa $n^{\circ} 1$ de $1^{\circ}$ de fevereiro de 2002. Regulamento técnico de identidade e de qualidade para a classificação da uva fina de mesa. Diário Oficial da República Federativa do Brasil, Brasília, 4 fev. 2002, Seção 1.7 p.

CASTRO, J.V. Resfriamento, embalagens e uso de dióxido de enxofre na conservação e na qualidade de uvas (Vitis vinifera L.) 'Itália' e 'Red Globe'. 1999. 109 f. Tese (Doutorado em Pré-Processamento de Produtos Agropecuários) - Universidade Estadual de Campinas, Faculdade de Engenharia Agrícola, Campinas, 1999.

CERMEÑN, Z.S. Estufas: instalação e manejo. Lisboa: Litexa, 1990. 355 p.

CUNHA, A.R. Parâmetros agrometeorológicos de cultura de pimentão (Capsicum annuum L.) em ambientes protegido e campo. 2001. 128 f. Tese (Doutorado em Energia na Agricultura) Universidade Estadual Paulista, Faculdade de Ciências Agronômicas, Botucatu, 2001.

FOOD AND AGRICULTURE ORGANIZATION OF THE UNITED NATIONS. FAOSTATAgriculture. Disponível em: <http://faostat.fao.org>. Acesso em: 8 mar. 2004.

GORGATTI NETTO, A.; GAYET, J.P.; BLEINROTH, E.W.; MATALLO, M.; GARCIA, E.; GARCIA, A.E.; ARDITO, E.F.G.; BORDIN, M. Uva para exportação: procedimentos de colheita e pós-colheita. Brasília: EMBRAPA-SPI, 1993. 40 p. (Série Publicações Técnicas - FRUPEX, 2). 
GRANGEIRO, L.C.; SOARES, J.M.; REIS, C.S.; GALVANINI, F.; SILVA, V.C. Armazenamento refrigerado de uva, cultivar Superior Seedless produzida no Vale do São Francisco. In: CONGRESSO BRASILEIRO DE FRUTICULTURA, 17., 2002, Belém. Anais... Belém: SBF/EMBRAPA, 2002. 1 CD ROM.

INSTITUTO DE ECONOMIA AGRÍCOLA. Anuário 2002: estatísticas da produção, São Paulo. v.14, n.1, p.1-316, 2003. (Série Informações Estatísticas da Agricultura)

OLIVEIRA, M.R.V. O emprego de casas de vegetação no Brasil: vantagens e desvantagens. Pesquisa Agropecuária Brasileira, Brasília, v.30, n.8, p.1049-60, 1995.

POMMER, C.V. Cultivares de uva produzidos ou introduzidos pelo IAC. In: SIMPÓSIO

BRASILEIRO SOBRE UVAS DE MESA, 1., 2000, Ilha Solteira. Anais... Ilha Solteira: FEIS-UNESP, 2001. p.51-67.

POMMER, C.V. Uva: tecnologia de produção, pós-colheita, mercado. Porto Alegre: Cinco Continentes, 2003. 778 p.

SOUZA, J.S.I.; MARTINS, F.P. Viticultura brasileira: principais variedades e suas características. Piracicaba: FEALQ, 2002. 368 p. 